PPPL-2926

UC-420,427

INTEGRAL EIGENMODE ANALYSIS OF SHEAR FLOW EFFECTS ON THE ION TEMPERATURE GRADIENT MODE

BY

M. ARTUN, J.V.W. REYNDERS AND W.M. TANG

JULY, 1993
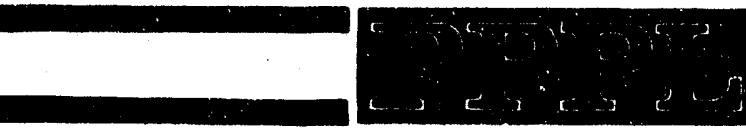

mancerton

mabma margice

LADOAatopr

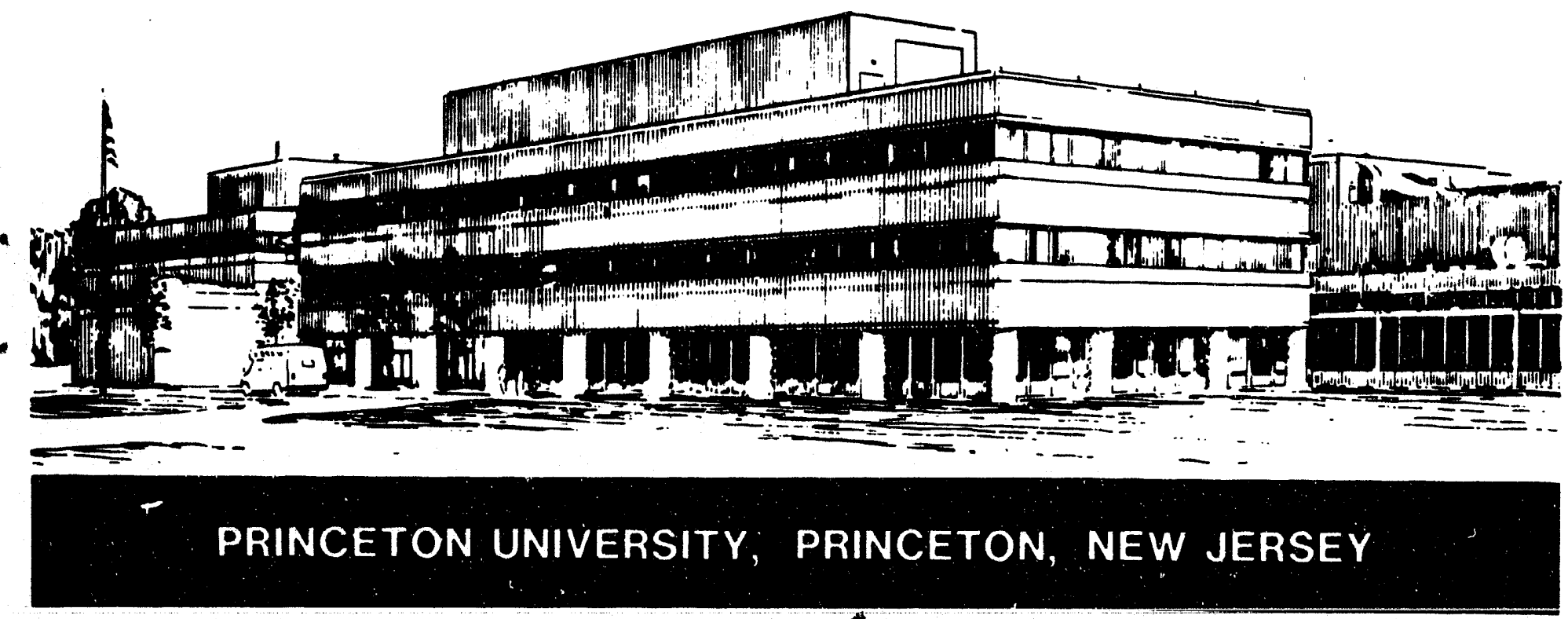




\section{NOTICE}

This report was prepared as an account of work sponsored by an agency of the United States Government. Neither the United States Government nor any agency thereof, nor any of their employees, makes any warranty, express or implied, or assumes any legal liability or responsibility for the accuracy, completeness, or usefulness of any information, apparatus, product, or process disclosed, or represents that its use would not infringe privately owned rights. Reference herein to any specific commercial produce, process, or service by trade name, trademark, manufacturer, or otherwise, does not necessarily constitute or imply its endorsement, recommendation, or favoring by the United States Government or any agency thereof. The views and opinions of authors expressed herein do not necessarily state or reflect those of the United States Government or any agency thereof.

\section{NOTICE}

This report has been reproduced from the best available copy.

Available in paper copy and microfiche.

Number of pages in this report: 31

DOE and DOE contractors can obtain copies of this report from:

Office of Scientific and Technical Information

P.O. Box 62

Oak Ridge, TN 37831;

(615) $576-8401$.

This report is publicly available from the:

National Technical Information Service

Department of Commerce

5285 Port Royal Road

Springfield, Virginia 22161

(703) $487-4650$ 
June 4,1993

\title{
Integral Eigenmode Analysis of Shear Flow Effects on the Ion Temperature Gradient Mode
}

\author{
M. Artun, J. V. W. Reynders; and W. M. Taing \\ Princeton Plasma Physics Laboratory \\ P.O. Box 451, Princeton, NJ 08543
}

\begin{abstract}
Previous numerical and analytic kinetic studies ${ }^{1-3}$ have investigated the influence of velocity shear on the ion temperature gradient (ITG) mode. These studies relied on a differential approximation to study mode structures with $k_{\perp} \rho_{i} \ll 1$. A recently developed gyrokinetic integral code is here used to explore the effects of sheared flows on the ITG mode for arbitrary values of $k_{\perp} \rho_{i}$. It is found that both the mode structure and eigenfrequencies predicted by the integral code can differ from the results obtained by the differential approach, even in the $k_{y} \rho_{i} \ll 1$ limit. Although some trends predicted by the differential approximation are recovered by the integral approach, there are some significant differences. For example, the slight destabilizing effect observed for small values of the perpendicular velocity shear at $k_{\perp} \rho_{i} \ll 1$ is amplified when the integral approach is applied. In dealing with the higher radial eigenmodes, which can often exhibit the largest growth rates, it is emphasized that their finer radial structure usually dictates that the integral equation analysis is required. Results from the integral code are presented together with comparisons with results from the differential approach.
\end{abstract}

* Permanent address: Los Alamos National Laboratory, Los Alamos, NM 87545 


\section{Introduction}

There is significant current interest in the fusion community about the effects of sheared equilibrium flows on tokamak energy confinement. This has been stimulated by recent experimental results from machines like D-IIID, ${ }^{4-6}$ TFTR $^{7}$ and JFT-2M ${ }^{8,9}$ which indicate that there is strong evidence that improved energy confinement in $\mathrm{H}$-mode (high density) discharges is linked to the presence of radially sheared poloidal flows. These flows can be generated by large radial electric fields near the edge of the plasma-a condition which is reported to be a prominent feature of most $\mathrm{H}$-mode discharges. For example, in the $\mathrm{CCT}^{10}$ experiment, where the electric field was externally generated, an $\mathrm{H}$-mode like discharge was obtained with associated poloidal flows. It is believed that sheared perpendicular flows have a strong stabilizing effect on the ion temperature gradient (ITG) driven instability which could play a major role in energy transport. Model calculations for kinetic long wavelength modes $\left(k_{\perp} \rho_{i}<1\right)$ and fluid modes in a sheared slab geometry have shown that large enough values of the perpendicular flow shear will uniformly stabilize the ITG mode. However. these calculations basically dealt with the $\ell=0$ (ground-state) mode and were limited to long perpendicular wavelengths (differential approach).

Radially sheared toroidal flows are present in discharges where unbalanced neutral beam injection heating is employed. These flows have a Kelvin-Helmholtz type destabilizing effect on the ITG instability. Both kinetic and fluid analyses in the long wavelength limit indicate that in sheared slab geometry, parallel (toroidal) sheared flows would be uniformly destabilizing. However, for large enough values of perpendicular shear flow the mode is again stabilized. It was reported ${ }^{1}$ that the relative sign of parallel and perpendicular flow is important for small values of perpendicular shear flow. Yet, the magnitude of perpendicular shear flow necessary for complete stabilization appears to be insensitive to the relative sign and magnitude of parallel shear flow present in the system.

In this paper we present solutions to the gyrokinetic integral eigenmode equation in a 
sheared slab geometry. The integral approach allows us to investigate arbitrary perpendicular wavelength modes with full finite larmor radius (FLR) effects. Hence, the higher radial eigenmodes, which display significant radial structure, can be properly treated. Although these modes may be less significant for transport, it is important to understand their behavior since in some cases for tokamak-like parameters, the $\ell=1$ or even the $\ell=2$ mode can have a larger growth rate than the $\ell=0$ (ground-state) mode.

The solution of the eigenmode equation is obtained in Fourier space. This allows the problem to be formulated as an integral equation. Using standard Galerkin techniques. the integral equation can be cast in a matrix equation form, which in turn is solved using efficient eigenvalue routines.

The remainder of this paper is organized as follows. In Sec. II.A we present the derivation of the integral eigenmode equation. Sec. II.B describes the numerical technique employed in this analysis. The numerical results are presented in Sec. III, and in Sec. IV we present a discussion about the differences and regions of validity of the differential and integral approaches. A summary and discussion is presented in Sec. V.

\section{Eigenmode Analysis of the ITG Instability}

The geometry used in the analysis is a sheared slab geometry where $x, y, z$ directions can be viewed as corresponding to the radial, poloidal, and toroidal directions respectively. and the equilibrium magnetic field is given by $\mathbf{B}=B\left[\hat{\mathbf{z}}+\left(x / L_{s}\right) \hat{\mathbf{y}}\right]$. We follow the usual ordering in the gyrokinetic equation, $\omega / \Omega_{i} \sim k_{\|} / k_{\perp} \sim \mathcal{O}\left(\rho_{i} / L\right)$ where $\omega$ is the eigenfrequency of the mode, $\Omega_{i}$ is the ion gyrofrequency, $\rho_{i}$ is the ion gyroradius, and $L$ is the shortest equilibrium scale length in the system. 


\section{A. Derivation of the Integral Eigenmode Equation}

Using the transformation ${ }^{1,11}$

$$
\begin{aligned}
& \mathbf{c}=\mathbf{v}-\mathbf{v}, \\
& \mathbf{R}=\mathbf{x}+\frac{\mathbf{c} \times \hat{\mathbf{b}}}{\Omega} \\
& E=\frac{c^{2}}{2} \\
& \mu=\frac{1}{B} \frac{c_{\perp}^{2}}{2}
\end{aligned}
$$

and defining

$$
g \equiv f-\frac{q}{m} \Phi \frac{\partial F(E, x)}{\partial E}
$$

with $f$ being the perturbed distribution function, the linearized electrostatic gyrokinetic equation in the presence of sheared flows ${ }^{1}$ can be written as:

$$
\begin{aligned}
\left(\frac{\partial}{\partial t}\right. & \left.+\mathbf{V} \cdot \nabla_{R}+c_{\|} \nabla_{R_{\|}}\right) g=\frac{q}{m} \nabla_{R} \bar{\Phi} \times \frac{\hat{\mathbf{b}}}{\Omega} \cdot \nabla_{R} F_{M} \\
& -\frac{q}{m} \frac{\partial F_{M}}{\partial E}\left(\frac{\partial}{\partial t}+\mathbf{V} \cdot \nabla_{R}\right) \bar{\Phi}-\frac{q}{m} \frac{\partial F_{M}}{\partial E}\left(\nabla_{R} \bar{\Phi} \times \frac{\hat{\mathbf{b}}}{\Omega} \cdot \nabla_{R} \mathbf{V} \cdot \hat{\mathrm{b}} c_{\|}\right)
\end{aligned}
$$

where $\Phi$ is the perturbed electrostatic potential, and the lowest order equilibrium electric field is given by $\nabla \Phi_{0}=\mathbf{V} \times \mathbf{B} / c$. Here, $\bar{\Phi} \equiv\langle\Phi\rangle_{\psi}, \Omega \equiv q B / m c$, and $\psi$ is the gyrophase angle. $\nabla_{R}$ denotes derivative with respect to the guiding center coordinate $\mathbf{R}$, and $\mathbf{V}$ is the equilibrium sheared flow. Allowing equilibrium density, temperature, and flow profiles in the $x$-direction leads to:

$$
\begin{aligned}
\nabla_{R} F_{M} & =-\frac{1}{L_{n}}\left[1+\eta\left(\frac{E}{T / m}-\frac{3}{2}\right)\right] F_{M} \hat{\mathbf{x}} \\
\text { and } & \\
\nabla \mathbf{V} \cdot \overrightarrow{\mathbf{b}} & =-\frac{1}{L_{n}} \vartheta v_{t} \hat{\mathbf{x}}
\end{aligned}
$$


where

$$
\begin{aligned}
L_{n} & \equiv-\frac{\partial \ln n_{0}}{\partial x} \\
\eta & \equiv \frac{\partial \ln T}{\partial \ln n_{0}} \\
\vartheta & \equiv \frac{\partial \ln V_{0 z}}{\partial \ln n_{0}}
\end{aligned}
$$

and $v_{t}=(2 T / m)^{1 / 2}$.

Normalizing $\Phi$ to $e / T_{e}$ and using

$$
\Phi=\sum_{l} \Phi_{l} \exp \left(i k_{l} x+i k_{y} y-i \omega t\right)
$$

we can express $\bar{\Phi}$ as

$$
\bar{\Phi}=\sum_{l} \Phi_{l} J_{0}\left(k_{l \perp}\right) \exp \left(i k_{l} R_{x}+i k_{y} R_{y}-i \omega t\right)
$$

with $k_{l \perp}^{2} \equiv\left(k_{l}^{2}+k_{y}^{2}\right) c_{\perp}^{2} / \Omega^{2}$. Taking the perturbation to be periodic in $x$ with a period of $2 x_{0}$ then allows $\Phi$ to be expressed as a Fourier series in $\left[-x_{0}, x_{0}\right]$. Since the $y$-direction is a direction of symmetry, it is appropriate to concentrate on a single $k_{y}$ mode. Since $k_{\|}=0$ on the mode rational surface corresponds to the most unstable case, we will only consider the $k_{z}=0$ case in this paper. Hence, defining

$$
\omega_{* e} \equiv \frac{c k_{y} T_{e}}{e B L_{n}}
$$

Eq. (3) for species $s$ can be written as

$$
\begin{gathered}
\left(\omega-k_{y} V_{0 y_{s}}-k_{\|} c_{\|}\right) g_{s}=+\alpha_{s} F_{M_{s}}\left(\omega-k_{y} V_{0 y_{s}}\right) \bar{\Phi} \\
+\omega_{* e} \bar{\Phi} F_{M_{\bullet}}\left[1+\eta_{s}\left(\bar{E}-\frac{3}{2}\right)+2 \vartheta_{s} \overline{c_{\|}}\right]
\end{gathered}
$$


with $\bar{E} \equiv E /(T / m), \overline{c_{\|}} \equiv c_{\|} / v_{t}$, and $\alpha_{s} \equiv\left(q_{s} / e\right)\left(T_{e} / T_{s}\right)$. It is important to note that in Eq. (7) all the quantities are in the guiding center coordinate $\mathbf{R}$. Using $n_{s}=\int \mathrm{d} \mathbf{v} f_{s}$ then yields:

$$
n_{s}=-\alpha_{s} \frac{e \Phi}{T_{e}}+\int \mathrm{d} \mathbf{v} g
$$

where

$$
\begin{aligned}
\int \mathrm{d} v g= & \int c_{\perp} \mathrm{d} c_{\perp} \mathrm{d} c_{\|} \mathrm{d} \psi\left[\frac{\alpha_{s}\left(\omega-k_{y} V_{0 y_{\odot}}\right)+\hat{\omega}_{* e}}{\omega-k_{y} V_{0 y_{\odot}}-k_{\|} c_{\|}}\right] \times \\
& \sum_{l} \mathrm{e}^{i k_{l} x+i k_{y} y+\left(i k_{l} \cos \psi-i k_{\mathrm{y}} \sin \psi\right) c_{\perp} / \Omega-i \omega t} J_{0}\left(k_{l \perp}\right) \Phi_{l} F_{M_{s}}
\end{aligned}
$$

with $\left[V_{0 y_{s}}, k_{\|}\right]=\left[V_{0 y_{s}}, k_{\|}\right]\left(x+c_{\perp} \cos \psi / \Omega\right)$, and

$$
\hat{\omega}_{* e} \equiv \omega_{* e}\left[1+\eta_{s}\left(\bar{E}-\frac{3}{2}\right)+2 \vartheta_{s} \overline{c_{\| l}}\right] .
$$

To facilitate the integration in the gyrophase angle $\psi$ the integration factor, ${ }^{12}$

$$
1=\int_{-\infty}^{\infty} \mathrm{d} x^{\prime} \delta\left(x^{\prime}-x-c_{\perp} \cos \psi / \Omega\right)=\int_{-\infty}^{\infty} \frac{\mathrm{d} k^{\prime} \mathrm{d} x^{\prime}}{2 \pi} \mathrm{e}^{-i k^{\prime}\left(x^{\prime}-x-c_{\perp} \cos \psi / \Omega\right)},
$$

can be utilized to interchange $x^{\prime}$ and $x+c_{\perp} \cos \psi / \Omega$ in Eq. (9). Using

$$
\int_{0}^{2 \pi} \mathrm{e}^{\left(i k^{\prime} \cos \psi-i k_{y} \sin \psi\right) c_{\perp} / \Omega}=2 \pi J_{0}\left(k_{\perp}^{\prime}\right)
$$

with $k_{\perp}^{\prime 2} \equiv\left(k^{\prime 2}+k_{y}^{2}\right) c_{\perp}^{2} / \Omega^{2}$, then gives

$$
\begin{aligned}
\int \mathrm{d} \mathbf{v} g= & \sum_{l} \mathrm{e}^{i k_{l} x+i k_{y} y-i \omega t} \int \mathrm{d} x^{\prime} \mathrm{d} k^{\prime} \mathrm{e}^{i\left(k_{l}-k^{\prime}\right)\left(x^{\prime}-x\right)} \times \\
& \int 2 \pi c_{\perp} \mathrm{d} c_{\perp} \mathrm{d} c_{\|} \frac{\alpha_{s}\left(\omega-k_{y} V_{0 y_{s}}\left(x^{\prime}\right)\right)+\hat{\omega}_{* e}}{\omega-k_{y} V_{0 y_{\iota}}\left(x^{\prime}\right)-k_{\|}\left(x^{\prime}\right) c_{\|}} J_{0}\left(k_{\perp}^{\prime}\right) J_{0}\left(k_{l \perp}\right) \Phi_{l} F_{M_{s}} .
\end{aligned}
$$

The velocity integrals are straightforward, ${ }^{13}$ and Eq. (9) yields

$$
\int \mathrm{d} \mathbf{v} g=-\sum_{l} \mathrm{e}^{i k_{l} x+i k_{y} x-i \omega t} \Phi_{l} n_{0,} \int \mathrm{d} x^{\prime} \mathrm{d} k^{\prime} \mathrm{e}^{i\left(k_{l}-k^{\prime}\right)\left(x^{\prime}-x\right)} \mathcal{G}_{s}\left(x^{\prime}, k_{l}, k^{\prime}\right)
$$


with

$$
\begin{gathered}
\mathcal{G}_{s}\left(x^{\prime}, k_{l}, k^{\prime}\right)=\left[\alpha_{s}+\frac{1}{\tilde{\Omega}}\left(1-\frac{2}{2} \eta_{s}\right) \zeta^{\prime} Z\left(\zeta^{\prime}\right) \Gamma_{0}\left(b_{a}, b_{g}\right)+\frac{2}{\tilde{\Omega}} \vartheta_{s} \zeta^{\prime}\left(1+\zeta^{\prime} Z\left(\zeta^{\prime}\right)\right) \Gamma_{o}\left(b_{a}, b_{g}\right)\right. \\
\left.+\frac{\eta_{s}}{\tilde{\Omega}} \zeta^{\prime 2}\left(1+\zeta^{\prime} Z\left(\zeta^{\prime}\right)\right) \Gamma_{0}\left(b_{a}, b_{g}\right)+\frac{\eta_{s}}{\tilde{\Omega}} \zeta^{\prime} Z\left(\zeta^{\prime}\right)\left[\Gamma_{0}\left(b_{a}, b_{g}\right)+b_{g} \Gamma_{1}\left(b_{a}, b_{g}\right)-b_{a} \Gamma_{0}\left(b_{a}, b_{g}\right)\right]\right]
\end{gathered}
$$

where $b_{a} \equiv\left(b+b^{\prime}\right) / 2, b_{g} \equiv \sqrt{b b^{\prime}}, b \equiv\left(k_{l}^{2}+k_{y}^{2}\right) \rho_{s}^{2}$, and $b^{\prime} \equiv\left(k^{\prime 2}+k_{y}^{2}\right) \rho_{s}^{2}$. Here $\rho_{\mathrm{s}} \equiv$ $v_{t_{s}} / \Omega$, is the Larmor radius of species $s, Z(\zeta)$ is the plasma dispersion function with $\zeta^{\prime}=\omega /\left(k_{y} x^{\prime} / L_{s}\right) v_{t_{s}}, \Gamma_{0}\left(b_{a}, b_{g}\right) \equiv \mathrm{e}^{-b_{a}} I_{0}\left(b_{g}\right)$, and $\Gamma_{1}\left(b_{a}, b_{g}\right) \equiv \mathrm{e}^{-b_{a}} I_{1}\left(b_{g}\right)$ where $I_{\nu}$ is the modified Bessel function.

The governing eigenmode equation for the perturbed electrostatic potential, $\Phi(\mathbf{x}, t)$. comes from the quasineutrality condition,

$$
\sum_{s} n_{s} q_{s}=0
$$

The solution of this equation is simplified in Fourier space. Representing $n_{s}(x)$ as a Fourier series in $\left[-x_{0}, x_{0}\right]$ yields

$$
n_{s}(x)=\sum_{m} \mathrm{e}^{i k_{m} x} n_{s}(m)
$$

where $n_{s}(m)$ is given by

$$
n_{s}(m)=\int_{-x_{0}}^{x_{0}} \frac{1}{2 \pi}-\mathrm{e}^{-i k_{m} x} \mathrm{~d} x
$$

Hence, the perturbed density response, Eq. (8), can be expressed as

$$
\begin{aligned}
n_{s}(m)= & -\sum_{l} \int_{-x_{0}}^{x_{0}} \mathrm{~d} x \mathrm{e}^{i\left(k_{l}-k_{m}\right) x+i k_{y} y-i \omega t} \Phi_{l} n_{0 s} \times \\
& {\left[\alpha_{s}+\int_{-\infty}^{\infty} \mathrm{d} x^{\prime} \mathrm{d} k^{\prime} \mathrm{e}^{i\left(k_{l}-k_{m}\right)\left(x^{\prime}-x\right)} \mathcal{G}_{s}\left(x, k_{l}, k^{\prime}\right)\right] . }
\end{aligned}
$$

The integral over $x, x^{\prime}, k^{\prime}$ can be simplified by changing the integration limits of $x^{\prime}$ to $\left[-x_{0}, x_{0}\right]$ and that of $x$ to $[-\infty, \infty]$. The integration over $x, k^{\prime}$ is then simply $\delta\left(k_{m}-k^{\prime}\right)$. 
This procedure is valid if we assume that $\Phi(x)$ is exponentialiy small outside the region $\left[-x_{0}, x_{0}\right]$. Eq. (15) can then be written as:

$$
\sum_{l} \mathcal{L}_{m l} \Phi_{l}=0
$$

where

$$
\begin{aligned}
\mathcal{L}_{m l}= & \delta_{m l}+\int_{-x_{0}}^{x_{0}} \mathrm{~d} x^{\prime} \mathrm{e}^{i\left(k_{l}-k_{m}\right) x^{\prime}} \mathcal{G}_{e}\left(x^{\prime}, k_{l}, k_{m}\right) \\
& -\sum_{j} Z_{j} f_{j}\left[\delta_{m l} \tau_{j} Z_{j}+\int_{-x_{0}}^{x_{0}} \mathrm{~d} x^{\prime} \mathrm{e}^{i\left(k_{l}-k_{m}\right) x^{\prime}} \mathcal{G}_{j}\left(x^{\prime}, k_{l}, k_{m}\right)\right]
\end{aligned}
$$

with $Z_{j}$ and $f_{j} \equiv n_{0 j} / n_{0 e}$ being the charge and fraction of ion species $j$. In the evaluation of $\mathcal{G}_{e}$ finite Larmor radius effects can be ignored thereby reducing $\mathcal{G}_{e}\left(\dot{x}^{\prime}, k_{l}, k_{m}\right)$ to $\mathcal{G}_{e}\left(x^{\prime}\right)$.

\section{B. Numerical Technique}

Eigenfrequencies and mode structures are found by finding nontrivial solutions to the matrix equation

$$
[\mathcal{L}][\Phi]=\mathbf{A b}=0
$$

which is accomplished by finding frequencies, $\omega$, which satisfy

$$
\operatorname{det}[\mathbf{A}]=|\mathbf{A}|=0
$$

This is equivalent to diagonalizing the matrix

$$
\mathbf{A} \rightarrow\left[\begin{array}{cccc}
\lambda_{1}(\omega) & & & 0 \\
& \lambda_{2}(\omega) & & \\
& & \ddots & \\
0 & & & \lambda_{N}(\omega)
\end{array}\right]
$$

and setting one or more of the diagonal elements to zero. From matrix theory, the diagonal functions, $\lambda_{n}(\omega)$, represent the eigenvalues of the matrix $\mathbf{A}$. Thus, the mode frequency and 
growth rate for the velocity sheared $\eta_{i}$ mode are obtained by solving $\lambda_{n}(\omega)=0$, and the associated eigenfunction yields the Fourier coefficients in $\Phi$ for the mode structure.

Given an initial guess for the real frequency and growth rate, a Newton's method is employed to converge to a zero eigenvalue of the matrix $\mathbf{A}$. It is efficient to solve for the eigenvalues at each iteration and use the smallest eigenvalue as the iteration parameter. The other alternative would be to calculate the determinant directly at each time step. Although this latter method involves a faster calculation, cases in which there is a wide spread in the magnitude of the eigenvalues will inhibit the convergence of the Newton's method. Hence, the former technique is employed.

It should be noted that the eigenvalue approach described does not guarantee convergence to the fastest growing root. Rather, the technique converges to the root closest to the initial guess provided to the Newton's method.

\section{Numerical Results}

In our analysis of the ITG-instability we have concentrated on typical tokamak parameters in an attempt to understand the linear stability behaviour of the mode with full FLR effects. Even though our code is able to treat nonadiabatic electrons and multiple ion species, in this paper we will consider adiabatic electrons and single ion species only. Our results basically conform with earlier findings in the small $k_{\perp} \rho_{i}$ limit. ${ }^{1-3}$ We are also able to recover the results from Linsker's ${ }^{12}$ and Dong's ${ }^{14}$ integral eigenmode calculations in the absence of sheared flows. The basic picture that the electrostatic ITG mode is linearly stable for large enough values of perpendicular flow shear is not altered. However, there are some interesting effects introduced by the proper treatment of instabilities at short perpendicular wavelengths. 


\section{A. Behaviour of the $\ell=0$ mode}

The stability properties of the $\ell=0$ mode under the influence of sheared flows was analyzed $^{1,2}$ in the kinetic, long perpendicular wavelength limit $\left(k_{\perp} \rho_{\mathrm{s}} \ll 1\right)$. It is observed that for large enough values of sheared perpendicular flow, the ITG-mode is linearly stable. In Fig. 1 we observe that there is a critical stabilizing value of perpendicular shear flow $\left(v_{y}^{\prime}\right)$ for each $k_{y} \rho_{s}$ value. However, it is interesting to note that for the $k_{y} \rho_{s}=1$ case, the mode is first destabilized for small values of $v_{y}^{\prime}$. This shows us that perpendicular shear flow can actually be rather strongly destabilizing at small values but eventually becomes stabilizing at sufficiently large $v_{y}^{\prime}$. Fig. 2 illustrates that the critical $v_{y}^{\prime}$ value required for stabilization increases as $k_{y} \rho$, increases.

Considering the effect of parallel shear flow alone, we find that the $\ell=0$ mode is not stabilized at large $k_{y} \rho_{s}$. In Fig. 3 the growth rate $(\gamma)$ and mode frequency $\left(\omega_{r}\right)$ are plotted against $k_{y} \rho_{s}$. The two branches of the $\ell=0$ mode first observed by Linsker ${ }^{12}$ are plotted in the absence of parallel shear flow. Branch I is stabilized around $k_{y} \rho_{s} \sim 1$ whereas Branch II, which is stable for $k_{y} \rho_{s}<1$, gets destabilized at large values of $k_{y} \rho_{s}$. Examining the behaviour of the growth rate and mode frequency in the presence of parallel shear flow. it is suggestive that parallel shear flow couples these two branches. For $v_{z}^{\prime} \neq 0$ the mode is uniformly unstable for the whole range of $k_{y} \rho_{s}$. In this case, the mode frequencies are similar to those of Branch I for $k_{y} \rho_{s}<1$. For larger values of $k_{y} \rho_{s}$, the mode frequencies increase and becorne more similar to those of Branch II.

The combined effect of parallel and perpendicular shear flow on the $\ell=0$ mode is displayed in Fig. 4, where several interesting features are notable. First of all, the originally stable mode is destabilized by parallel flow shear, $v_{z}^{\prime}$, in the absence of perpendicular shear flow $\left(v_{y}^{\prime}=0\right)$. This is due to the fact that parallel shear flow introduces an extra source of free energy that can destabilize the mode. Similarly, the destabilizing effect of perpendicular shear flow, $v_{y}^{\prime}$, can be seen in the same figure. Earlier studies in the long 
wavelength limit ${ }^{1}$ have shown that the relative sign of parallel and perpendicular shear can be quite important. This feature is present in Fig. 4. We observe that for the case of $v_{z}^{\prime}=0.5$, the stabilizing values of perpendicular flow shear flow are $v_{y}^{\prime}:=0.55$, and $v_{y}^{\prime}=-0.2$. It is worthwhile to note that the opposite would be true for $v_{z}^{\prime}=-0.5$, i.e.; in that case the mode would be stabilized at $v_{y}^{\prime}=-0.55$ and $v_{y}^{\prime}=0.2$, which is a mathematical property of the kernel. ${ }^{1}$

Defining the mode width as:

$$
\Delta x=\left[\frac{\sum_{l} k_{l} \Phi_{l}}{2 \pi \sum_{l} \Phi_{l}}\right]^{-1},
$$

the familiar heuristic estimate of the transport coefficient can be expressed as:

$$
\chi_{i}=\gamma(\Delta x)^{2}
$$

To assess possible transport implications, we plot the transport coefficient and mode width vs. perpendicular shear flow at different values of parallel shear flow in Fig. 5. It is evident here that parallel shear flow increases both the growth rate and mode width thereby giving. rise to 2 large transport coefficient. Similarly, comparing Fig. 4 and Fig. 5, we observe that there is a strong correlation between growth rates and mode widths. As perpendicular shear flow is introduced, for small values of $v_{y}^{\prime}$ the mode gets wider and the growth rate increases. For $v_{z}^{\prime}=0.5$, the maximum value of transport coefficient, $\chi_{i}$, is larger than the maximum value for the case without parallel flow shear by an order of magnitude. At large values of $v_{y}^{\prime}$ both the mode width and growth rate decrease such that transport coefficient is reduced.

\section{B. Behaviour of the $\ell=1$ mode}

The $\ell=1$ mode which exhibits more radial structure than the ground-state $(\ell=0)$ mode, is more sensitive to perpendicular velocity shear. For tokamak-like parameters. the $\ell=1$ or even the $\ell=2$ can have $a$ larger growth rate than the giounid-state mode. 
Even though the associated linear transport coefficient, $\chi_{i}$, will be smaller for higher radial eigenmodes, our analysis shows that these modes can exist at perpendicular shear flow levels where the ground state mode is stable. One such comparison is presented in Fig. 6 where the most unstable growth rate for the $\ell=0$ and $\ell=1$ modes are plotted. We observe that in the absence of shear flow, the $\ell=1$ mode has a larger growth rate than the $\ell=0$ mode. As the shear parameter is increased, both modes are stabilized, and $v_{y c r i t}^{\prime}$ for the $\ell=1$ mode is larger th?n that of the $\ell=0$ mode. The kink in the growth rate curve for the $\ell=1$ mode is due to destabilization of another branch which is discussed below.

Similar to the destabilization of the second branch ${ }^{12}$ of the ITG mode at large values of $k_{y} \rho_{s}$, perpendicular shear flow can destabilize a second branch. In Fig. 7 we plot the growth rate and real frequency vs. $v_{y}^{\prime}$ for two branches of the $\ell=1$ mode. Branch II. which is stable at low values of $v_{y}^{\prime}$, becomes unstable around $v_{y}^{\prime}=0.023$ and eventually assumes a larger growth rate than Branch I, which was the originally unstable branch. It is suggestive that this effect is dominant near marginal stability. Comparing Fig. $6\left(\eta_{i}=2.5\right)$ and Fig. $i$ $\left(\eta_{i}=3\right)$ it is seen that the destabilization of the second branch is more pronounced in the case with $\eta_{i}=2.5$, which is closer to the marginally stable $\eta_{i} \simeq 2$ value. In Fig. 8 the mode structure of the two branches corresponding to the parameters in Fig. $i$ is plotted at $v_{y}^{\prime}=0.3$ and $v_{y}^{\prime}=0.4$. At both values of $v_{y}^{\prime}$, the eigenfunctions of the two branches are similar. At $v_{y}^{\prime}=0.3$ Branch I is more unstable than Branch II, and at $v_{y}^{\prime}=0.4$ the opposite is true.

Another interesting feature introduced by perpendicular shear flow is the change of the envelope of the eigenfunction, $|\Phi|$. In the absence of shear flow the kernel is symmetric around $x=0$ and $\Phi(0)=0$, such that the $|\Phi|$ exhibits a double humped character. However, in Fig. 8 we see that as perpendicular flow shear is increased, $|\Phi|$ becomes single humped near stabilization. 


\section{Comparison of Differential and Integral Approaches}

In the long wavelength limit, the Bessel functions that appear in the gyrokinetic equation can be Taylor expanded to first order in $k_{\perp} \rho_{s}$. The perpendicular wavelength $k_{\perp}^{2} \equiv k_{x}^{2}+k_{y}^{2}$ can then be treated as an operator and the eigenmode equation can be cast in a differential equation form. The advantage of using the differential equation technique is that it is much easier to formulate and solve than the integral equation method described in the previous section. However, it is important to realize that this method is only valid for $k_{\perp} \rho_{s} \ll 1$. Choosing $k_{y} \rho_{s} \ll 1$ does not guarantee that $k_{x}$ will also be small. The mode width in the $x$-direction is controlled by the parameters $\eta_{i}$ and $\tau$, and, based on analytic estimates in the fluid regime, $\Delta x \sim \rho_{s} \sqrt{\left(1+\eta_{i}\right)} / \tau$. One crucial point in the integral treatment is the importance of the Bakshi-Linsker term ${ }^{15,12}$ which is introduced through the proper treatment of the resonant denominator, $\omega-k_{\|} v_{\|}$. The fact that $k_{z}=0$ in the shear slab analysis requires $k_{\|}$to be treated carefully. Near $x=0$, the distinction between the lab and guiding center coordinates becomes important since $k_{\|}=k_{y}\left(x / L_{s}\right)$. This was first observed by Bakshi, and was subsequently adapted by Linsker in the integral eigenmode analysis he carried out. Our analysis shows that in addition to being important for large $k_{\perp} \rho_{s}$, this term can also significantly influence modes localized away from the rational surface (e.g., cases with pure parallel velocity shear ${ }^{1}$ ). The omission of the Bakshi-Linsker term can introduce artificial radial structure to the mode. This is illustrated in Fig. 10 where the eigenfunctions obtained by differential, integral, and improper integral (Bakshi-Linsker term omitted) calculations for $v_{z}^{\prime}=0$, and $v_{z}^{\prime}=0.5$ are plotted. For $v_{z}^{\prime}=0$, the width of the eigenfunction is largest in the differential treatment, and the strong radial structure is visible in the improper integral treatment. However, as parallel flow shear is introduced, the eigenmodes obtained by the different types of calculations begin to look similar, and, again, the eigenfunction for the improper integral treatment is narrower. In Fig. 9 we observe that as $v_{z}^{\prime}$ is increased, the average radial wavenumber 
of the mode decreases and the discrepancy in the growth rates obtained by the different methods is diminished.

\section{Conclusions and Discussions}

In this work we have presented a kinetic integral eigenmode analysis of the ion temperature gradient instability. The governing eigenmode equation for low-frequency microinstabilities is formulated to incorporate parallel and perpendicular sheared flows. We have also taken into account the Bakshi-Linsker term which can be important in the vicinity of the rational surface in a sheared slab geometry. The numerical solution of the integral equation is carried out in Fourier space, and an efficient new code has been deviloped for this purpose. In the absence of flows our code recovers results from previous integral eigenmode studies. ${ }^{12,14}$ When the Bessel functions are expanded to first order in the argument in the new code, earlier results ${ }^{1,16,2}$ obtained in differential limit are also readily recovered.

Our analysis shows that for sufficiently large values of parallel shear flow and tokamaklike parameters, the whole spectral range can be unstable. This effect can be attributed to the coupling of two unstable branches ${ }^{12}$ of the ITG mode at short wavelengths. However, as shown in previous differential analyses, ${ }^{1}$ large enough values of perpendicular shear flow can again stabilize the mode. The asymmetric behaviour of the growth rate with respect to the relative sign of parallel and perpendicular shear flow ${ }^{1}$ is even more emphasized at short wavelengths. It was reported earlier that at small values of $v_{y}^{\prime}$, perpendicular shear flow may be either stabilizing of destabilizing depending on the sign of $v_{z}^{\prime} v_{y}^{\prime}$, but the stabilizing value of $v_{y}^{\prime}$ was shown to be weakly sensitive to the amount of parallel shear flow present. Our findings indicate that for $k_{\perp} \rho_{\mathrm{a}} \sim 1$, a small amount of perpendicular shear flow can actually destabilize a stable mode, even in the absence of parallel shear flow. When both parallel and perpendicular shear flow is considered, the stabilizing value of perpendicular shear flow can be quite different depending on the relative sign and magnitude of the 
parallel shear flow parameter.

It should be cautioned that the present results obtained for sheared slab geometry may not be readily applicable to toroidal geometry. Toroidal effects, such as curvature, grad-B. coriolis, and centrifugal drifts, and poloidal mode coupling can play an important role in the stability property of the ITG-mode with sheared flows. Nevertheless, certain key trends. such as the destabilizing influence of parallel shear flows and the stabilizing influence of perpendicular shear flows, are expected to persist. As an example, a direct extrapolation of these sheared slab results to toroidal geometry would imply that for realistic tokamak configurations with medium aspect ratio, unbalanced neutral beam injection could cause enough perpendicular shear flow to stabilize the toroidal ITG mode (especially at long wavelengths). Larger values of toroidal rotation are expected to be necessary to produce stability at shorter wavelengths. The results presented in this paper should serve as a useful benchmark for nonlinear numerical studies in the sheared slab involving gyrokinetic particle and gyrofluid simulations. For example, the self-generated shear flow observed in gyrofluid simulations ${ }^{17}$ and noted to be critical for the nonlinear saturation of the ITG instability, is very similar to the stabilizing perpendicular shear flow values presented in this paper. The ultimate goal of these kinetic studies is to extend the analysis to full toroidal geometry and include all relevant toroidal effects to realistically assess the behaviour of the global ITG and trapped-ion instabilities.

\section{Acknowledgements}

This work was supported by U.S. Department of Energy Contract No. DE-AC02-76CH03073. 


\section{Figures}

FIG. 1. Growth rate and real frequency vs. $v_{y}^{\prime}$ for various $k_{y} \rho_{s}$ values. Here, $L_{n} / L_{s}=$ $0.1, \tau=1, v_{z}^{\prime}=0$, and $L_{T} / L_{v}=1$.

FIG. 2. Perpendicular velocity shear required for stabilization of the $\ell=0$ mode, $v_{y c r i t}^{\prime}$, vs. $k_{y} \rho_{s}$. All other parameters are as in Fig. 1

FIG. 3. Growth rate vs. $k_{y} \rho_{s}$ for the $\ell=0$ mode with $\eta_{i}=3, L_{n} / L_{s}=0.1, k_{y} \rho_{s}=$ $0.316, \tau=1, v_{y}^{\prime}=0$, and $L_{T} / L_{v}=1$.

FIG. 4. Growth rate and real frequency vs. $v_{y}^{\prime}$ for the $\ell=0$ mode where $L_{n} / L_{s}=0.1, \tau=$ $1, L_{T} / L_{v}=1$, and $k_{y} \rho_{\mathrm{s}}=1$.

FIG. 5. $\chi_{i}$ and mode width vs. $v_{y}^{\prime}$ for the $\ell=0$ mode. All parameters are the same as in Fig. 4.

FIG. 6. Growth rate vs. $v_{y}^{\prime}$ for the for the $\ell=0,1$ modes. $\eta_{i}=2.5, L_{n} / L_{s}=0.1, k_{y} \rho_{s}=$ $0.316, \tau=1, v_{z}^{\prime}=0$, and $L_{T} / L_{v}=1$.

FIG. 7. Growth rate vs. $v_{y}^{\prime}$ for the two branches of the $\ell=1$ mode. $\eta_{i}=3, L_{n} / L_{s}=$ $0.1, k_{y} \rho_{s}=0.316, \tau=1, v_{z}^{\prime}=0$, and $L_{T} / L_{v}=1$

FIG. 8. Eigenfunctions of the two branches of the $\ell=1$ mode at $v_{y}^{\prime}=0.03,0.04$ for $\eta_{i}=3, L_{n} / L_{s}=0.1, k_{y} \rho_{s}=0.316, \tau=1, v_{z}^{\prime}=0$, and $L_{T} / L_{v}=1$. Here solid, dotted. and dot-dashed lines correspond to $\operatorname{Re}[\Phi], \operatorname{Im}[\Phi]$, and $|\Phi|$.

FIG. 9. Growth rate $(\gamma)$ and average wavenumber $\left(\left\langle\left|k_{x}\right|\right\rangle\right)$ vs. $v_{z}^{\prime}$ for the integral, integral without the Bakshi-Linsker term, and differential approaches. Here, $\eta_{i}=3, \tau=$ $1, L_{n} / L_{s}=0.1, v_{y}^{\prime}=0$, and $L_{T} / L_{v}=1$. 
FIG. 10. Eigenfunctions obtained by the integral, integral without the Bakshi-Linsker term, and differential approaches at $v_{z}^{\prime}=0$ and $v_{z}^{\prime}=0.5$. All other parameters are as in Fig. 9. 


\section{References}

${ }^{1}$ M. Artun and W. M. Tang, Phys. Fluids B 4, 1102 (1992).

${ }^{2}$ G. M. Staebler and R. R. Dominguez, Nucl. Fusion 31, 1891 (1991).

${ }^{3}$ X. H. Wang, P. H. Diamond, and Rosenbluth, Phys. Fluids B 4, 2402 (1992).

${ }^{4}$ K. H. Burrell, S. L. Allen, G. Bramson, N. H. Brooks, R. W. Callis, T. N. Carlstrom, M. S. Chu, A. P. Colleraine, D. Content, J. C. DeBoo, R. R. Dominguez, J. R. Ferron, R. L. Freeman, P. Gohil, C. M. Greenfield, R. J. Groebner, G. Haas, W. W. Heidbrink. D. N. Hill, F. L. Hinton and R.-M. Hong, W. Howl, C. L. Hsieh, G. L. Jackson. G. L. Jahns, R. A. James, A. G. Kellman, J. Kim, L. L. Lao, E. A. Lazarus, T. Lehecka. J. Lister, J. Lohr, T. C. Luce, J. L. Luxon, M. A. Mahdavi, H. Matsumoto, M. Mayberry, C. P. Moeller, Y. Neyatani, T. Ohkawa, N. Ohyabu, T. Okazaki, T. H. Osborne, D. O. Overskei, T. Ozeki, A. Peebles, S. Perkins, M. Perry, P. J. Petersen, T. W. Petrie. R. Philipona, J. C. Philips, R. Pinsker, P. A. Politzer, G. D. Porter, R. Prater, M. E. Rensink, M. J. Schaffer, D. P. Schissel, J. T. Scoville, R. P. Seraydarian, M. Shimada, T. C. Simonen, R. T. Snider, G. M. Staebler, B. W. Stallard, R. D. Stambaugh, R. D. Stav, H. St. John, R. E. Stockdale, E. J. Strait, P. L. Taylor, T. S. Taylor, P. K. Trost. U. Stroth, R. E. Waltz, S. M. Wolfe, R. D. Wood, and D. Wroblewski, Plasma Physics and Controlled Fusion 31, 1649 (1989).

${ }^{5}$ K. H. Burrell and T. N. Carlstorm and E. J. Doyle and P. Gohil and R. J. Groebner and T. Lehecka and N. C. Luhmann Jr. and H. Matsumoto and T. H. Osborne and W. A. Peebles and and R. Philipona, Phys. Fluids B 2, 1405 (1990).

${ }^{6}$ R. J. Groebner, K. H. Burrell, and R. P. Seraydarian, Phys. Rev. Let. 64, 3015 (1990).

${ }^{7}$ R. J. Fonck, R. Howell, K. Jaehnig, L. Roquemore and G. Schilling, S. Scott, M. C. Zarnstorff, C. Bush, R. Goldston, H. Hsuan, D. Johnson, A. Ramsey, J. Schivell, and 
H. Towner, Phys. Rev. Let. 63 (1989).

${ }^{8}$ Ida, K. and Hidekuma, S. and Miura, Y. and Fujita, T. and Mori, M. and Hoshino, K. and Suzuki, N. and Yamauchi, T. and the JFT-2M Group, Phys. Rev. Let. 65, 1364 (1990).

${ }^{9}$ K. Ida, S. Hidekuma, M. Kojima, Y. Miura, S. Tsuji, K. Hoshino, M. Mori, N. Suzuki. T. Yamauchi, and the JFT-2M Group, Phys. Fluids B 4, 2552.

${ }^{10}$ R. J. Taylor, M. L. Brown, B. D. Fried, H. Grote, J. R. Liberati, G. J. Morales, P. Pribyl. D. Darrow, and M. Ono, Phys. Rev. Let. 63, 2365 (1989).

${ }^{11}$ P. J. Catto, Plasma Physics 20, 719 (1978).

${ }^{12}$ R. Linsker, Phys. Fluids 24, 1485 (1981).

${ }^{13}$ G. N. Watson, Theory of Bessel Functions, Cambridge University Press, Cambridge. Massachussetts, 1958.

${ }^{14}$ J. Q. Dong, P. N. Guzdar, and Y. C. Lee, Phys. Fluids 30, 2694 (1987).

${ }^{15}$ P. Bakshi, W. Bellew, G. Ganguli, and P. Satyaranayana, 1977, In Proceedings of the 1977 Sherwood Theory Conference (San Diego, CA).

${ }^{16}$ T. S. Hahm and W. M. Tang, Phys. Fluids 31, 1185 (1988).

${ }^{17}$ G. W. Hammett, M. A. Beer, W. Dorland, S. C. Cowley, and S. A. Smith, Developments in the Gyrofluid Approach to Tokamak Turbulence Simulations, Plasma Physics and Controlled Fusion, (accepted for publication), 1993. 


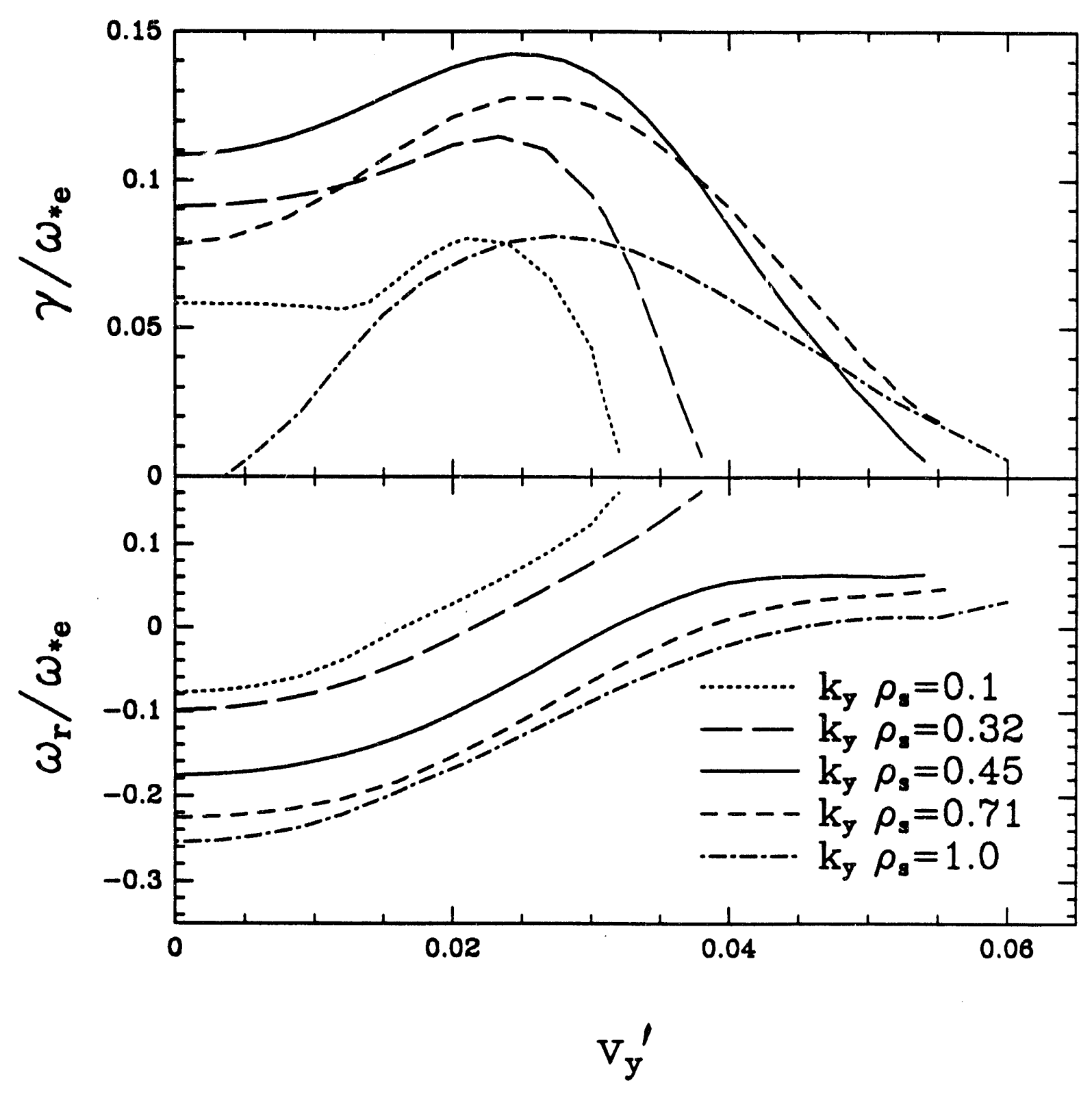

Figure 1: Growth rate and real frequency vs. $v_{y}^{\prime}$ for various $k_{y} \rho_{s}$ values. Here, $L_{n} / L_{s}=$ $0.1, \tau=1, v_{z}^{\prime}=0$, and $L_{T} / L_{v}=1$. 


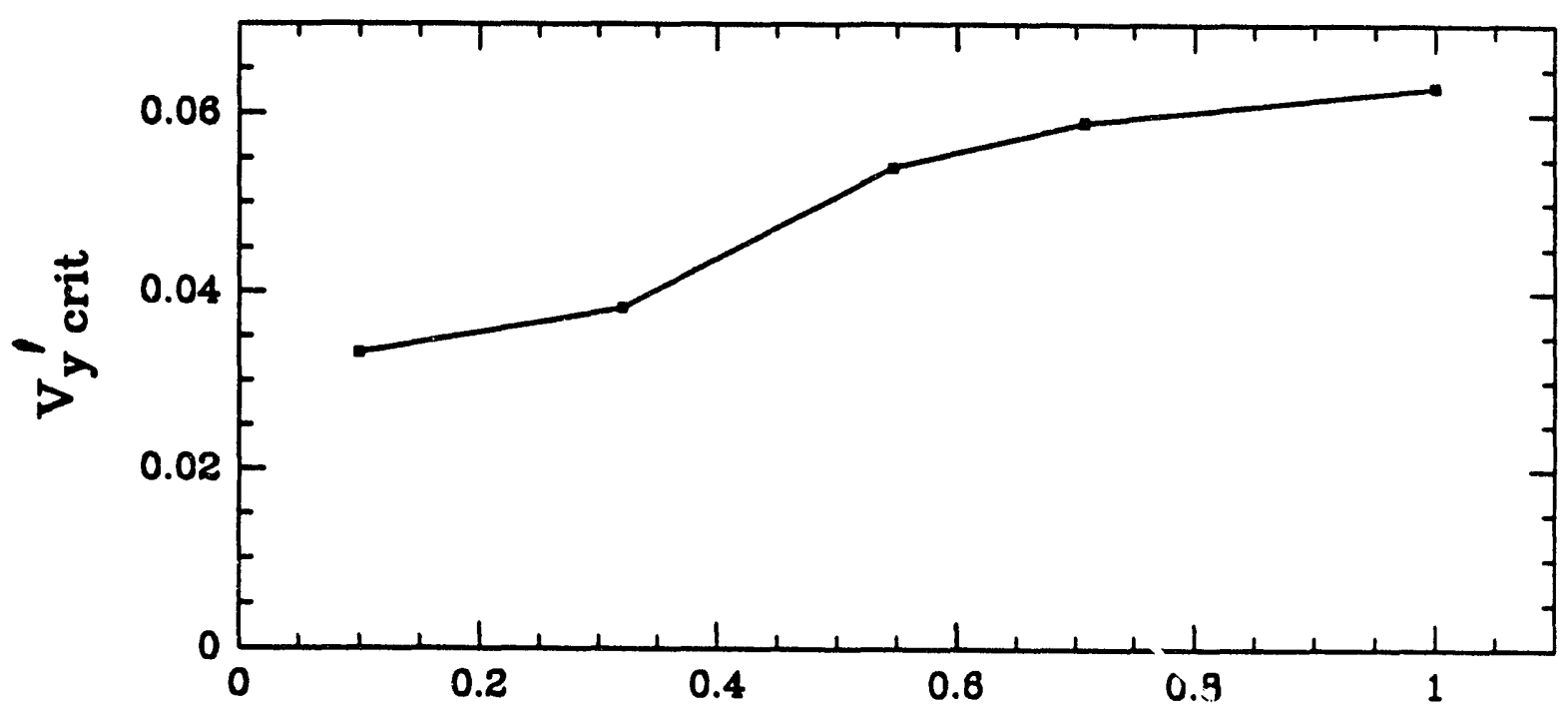

$k_{\mathrm{y}} \rho_{\mathrm{s}}$

Figure 2: Perpendicular velocity shear required for stabilization of the $\ell=0$ mode, $v_{y c r i t}^{\prime}$, vs. $k_{y} \rho_{\dot{s}}$. All other parameters are as in Fig. 1. 


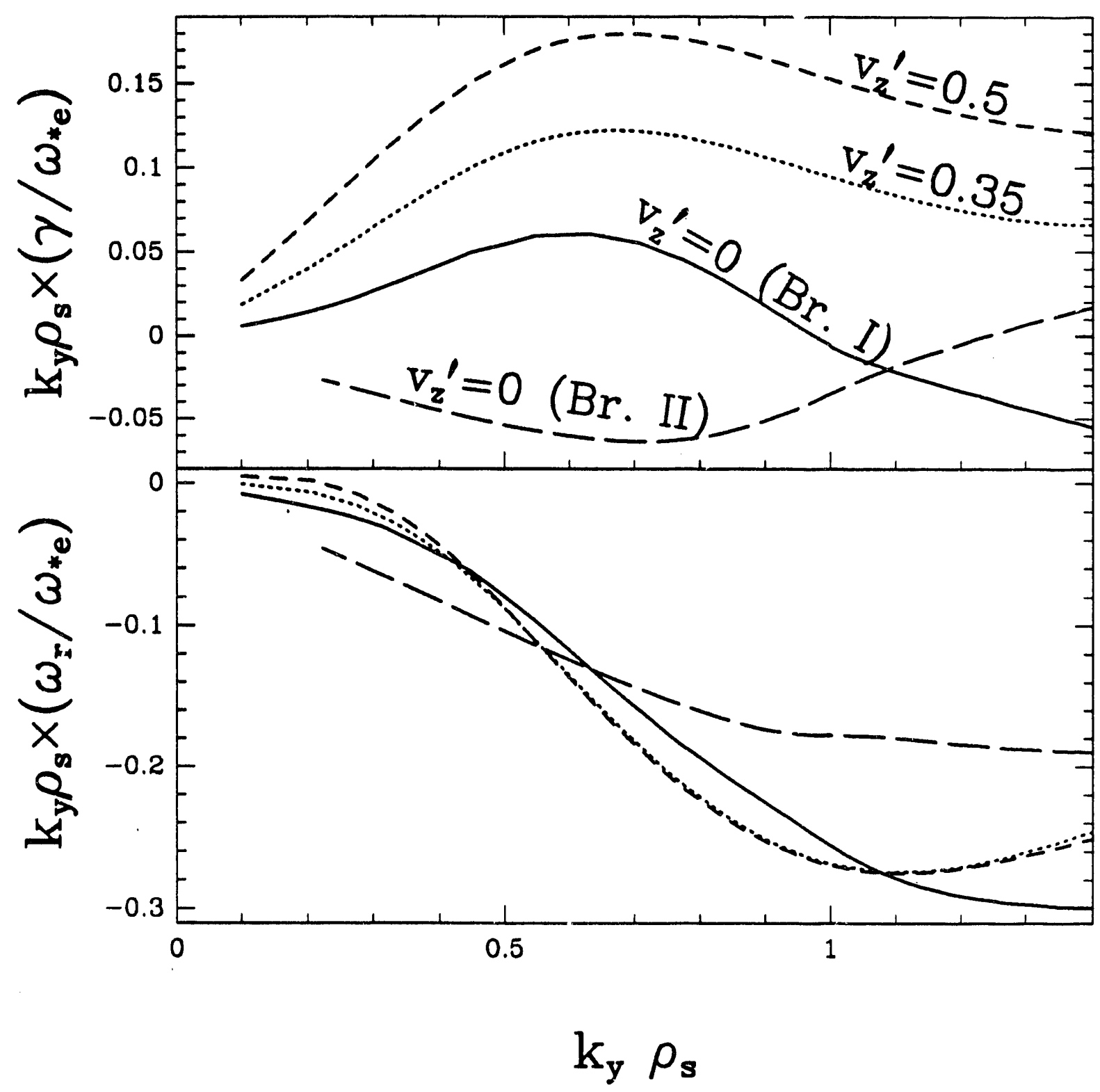

Figure 3: Growth rate vs. $k_{y} \rho_{s}$ for the $\ell=0$ mode with $\eta_{i}=3, L_{n} / L_{s}=0.1, k_{y} \rho_{s}=$ $0.316, \tau=1, v_{y}^{\prime}=0$, and $L_{T} / L_{v}=1$. 


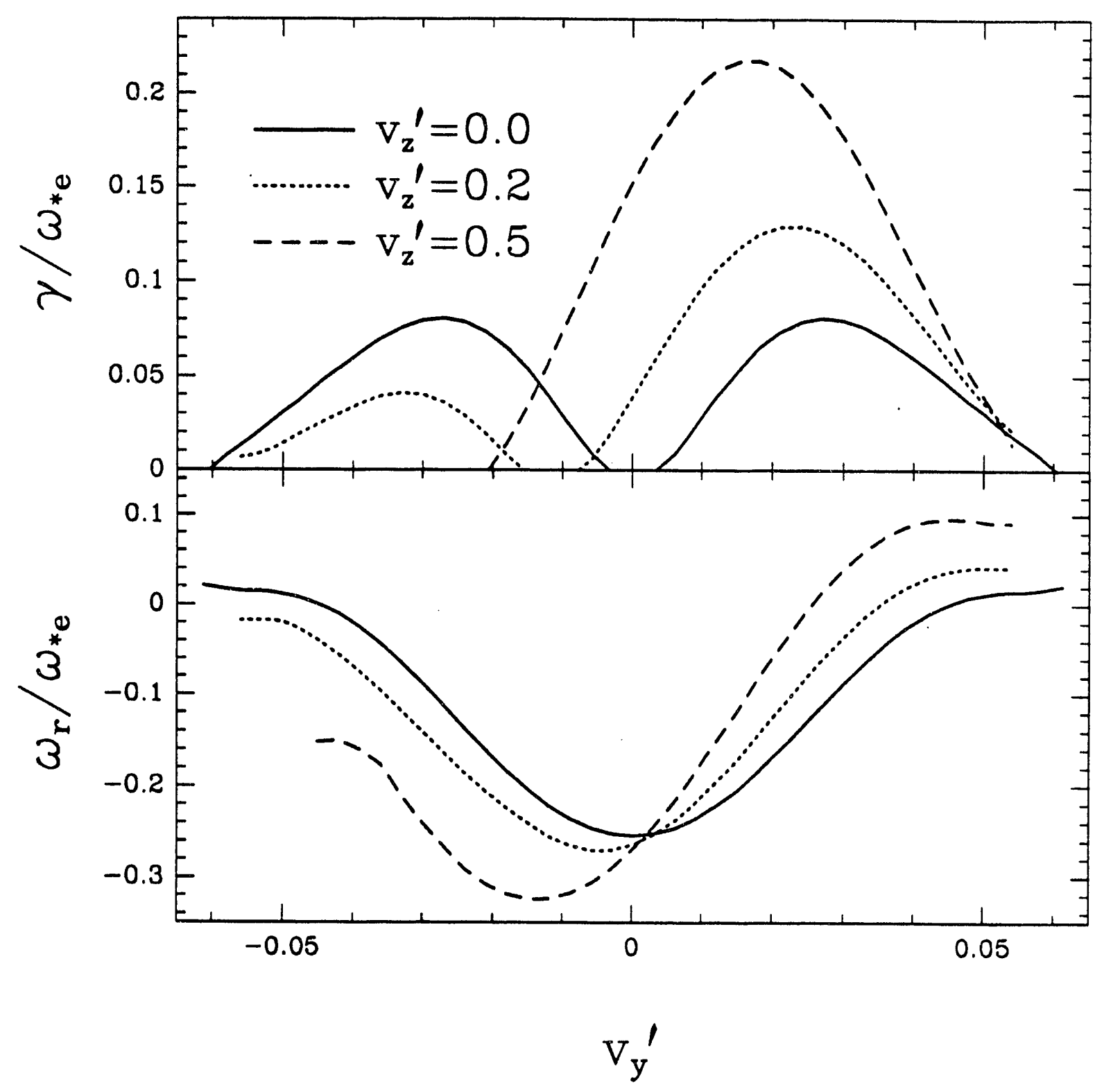

Figure 4: Growth rate and real frequency vs. $v_{y}^{\prime}$ for the $\ell=0$ mode where $L_{n} / L_{s}=0.1, \tau=$ $1, L_{T} / L_{v}=1$, and $k_{y} \rho_{s}=1$. 


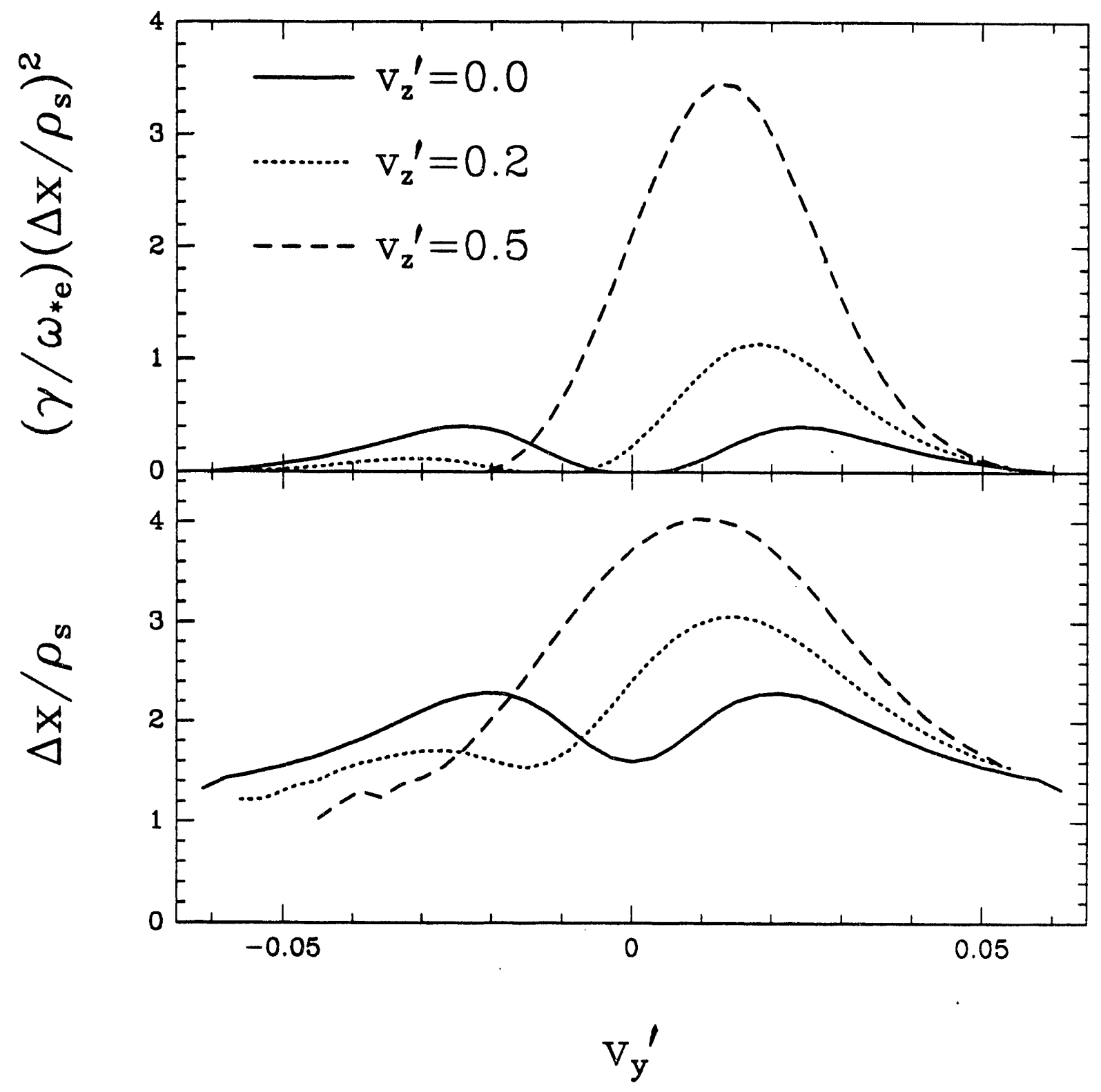

Figure 5: $\chi_{i}$ and mode width vs. $v_{y}^{\prime}$ for the $\ell=0$ mode. All parameters are the same as in Fig. 4. 


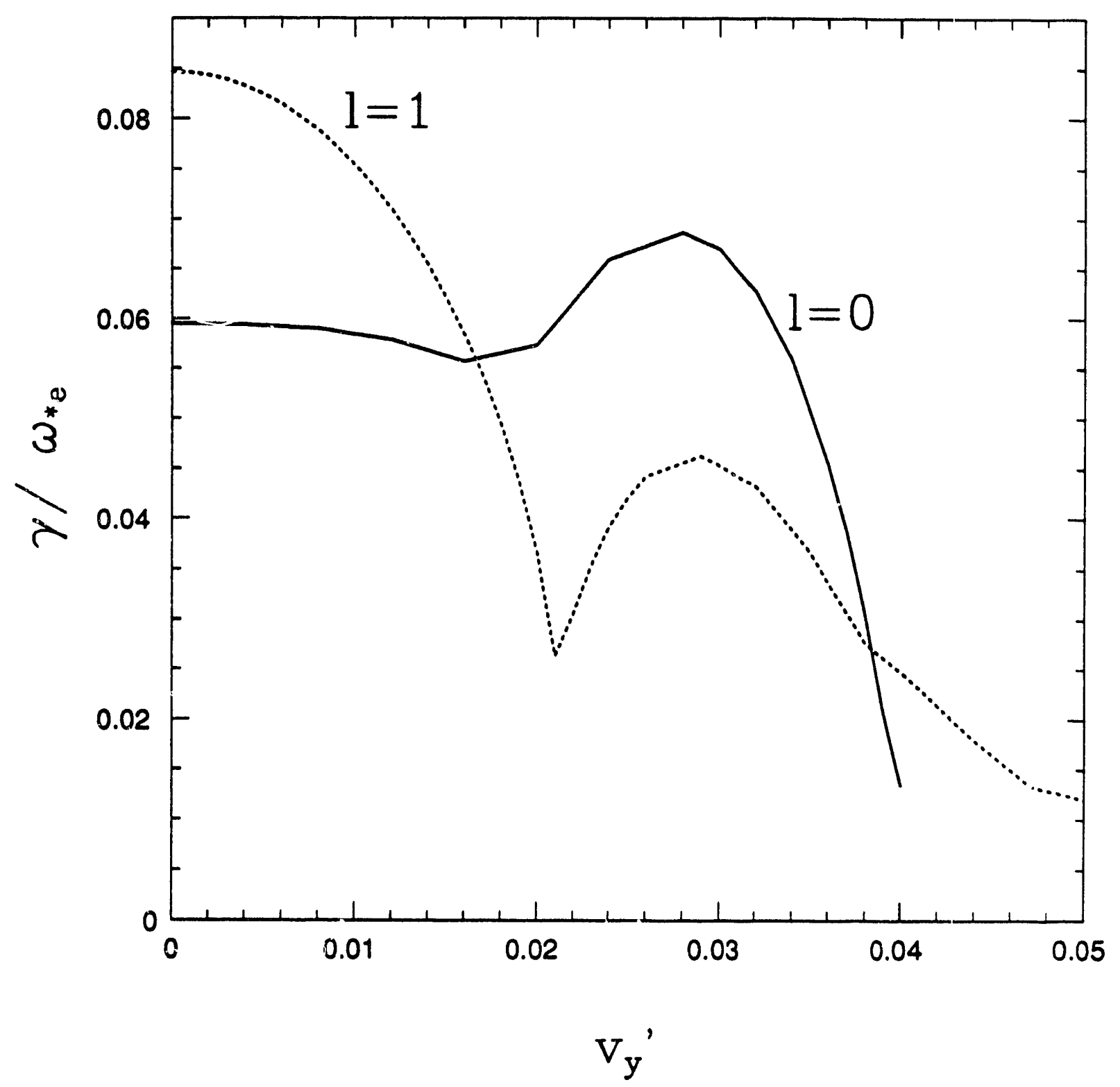

Figure 6: Growth rate vs. $v_{y}^{\prime}$ for the for the $\ell=0,1$ modes. $\eta_{i}=2.5, L_{n} / L_{s}=0.1, k_{y} \rho_{s}=$ $0.316 \tau=1, v_{z}^{\prime}=0$, and $L_{T} / L_{v}=1$. 


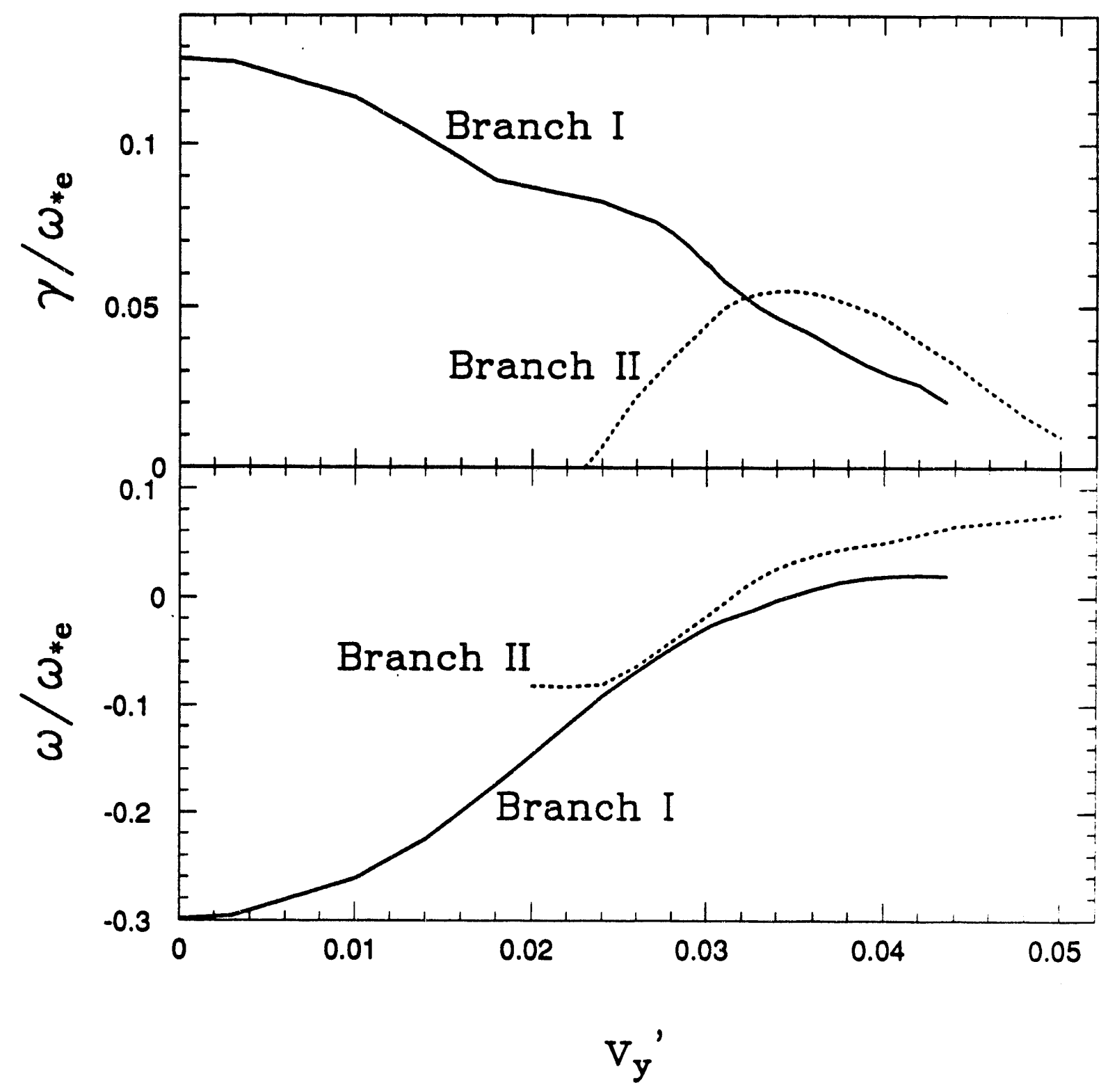

Figure 7: Growth rate vs. $v_{y}^{\prime}$ for the two branches of the $\ell=1$ mode. $\eta_{i}=3, L_{n} / L_{s}=$ $0.1, k_{y} \rho_{s}=0.316, \tau=1, v_{z}^{\prime}=0$, and $L_{T} / L_{v}=1$ 


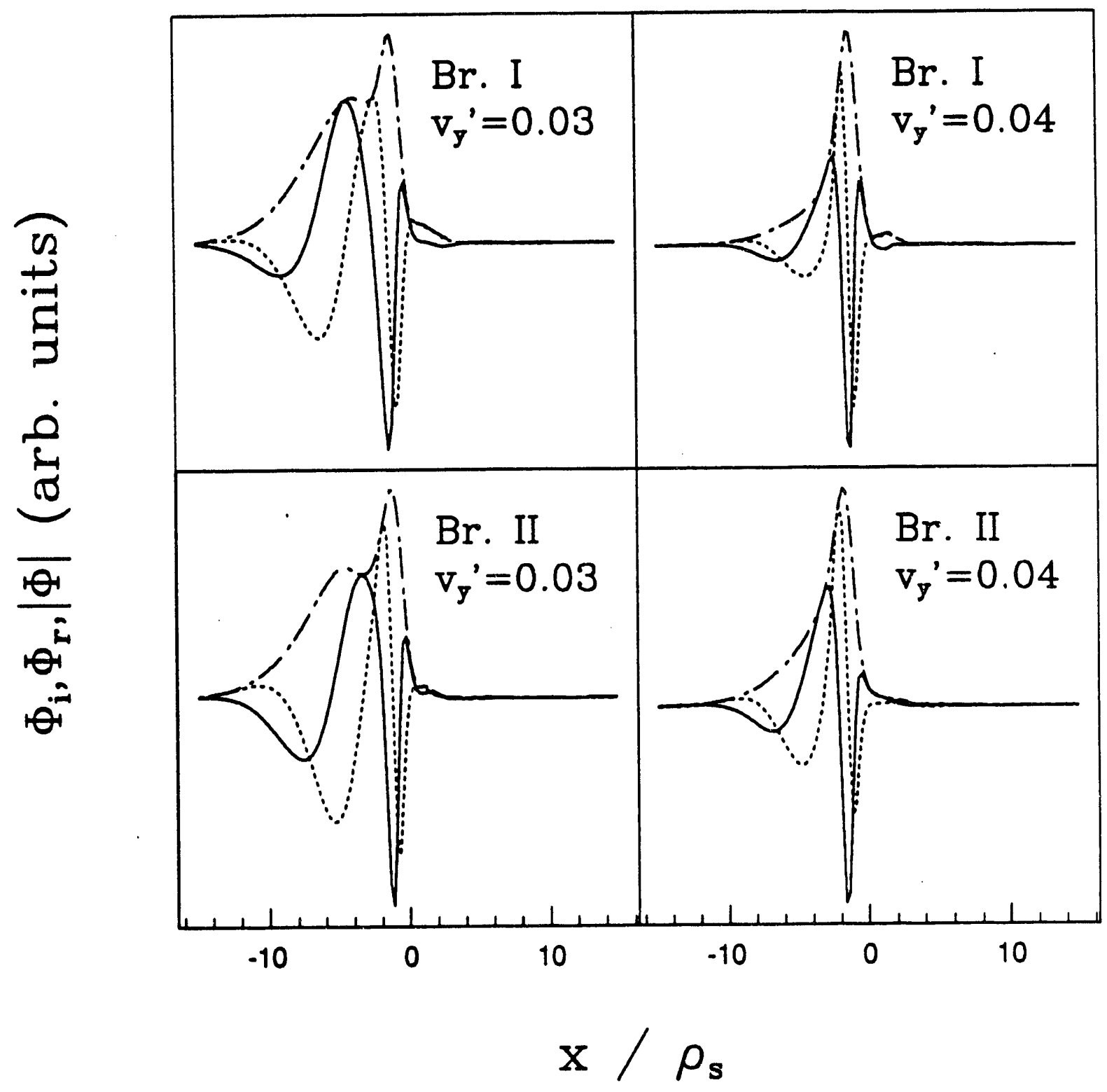

Figure 8: Eigenfunctions of the two branches of the $\ell=1$ mode at $v_{y}^{\prime}=0.03,0.04$ for $\eta_{i}=3, L_{n} / L_{s}=0.1, k_{y} \rho_{s}=0.316, \tau=1, v_{z}^{\prime}=0$, and $L_{T} / L_{v}=1$. Here solid, dotted, and dot-dashed lines correspond to $\operatorname{Re}[\Phi], \operatorname{Im}[\Phi]$, and $|\Phi|$. 


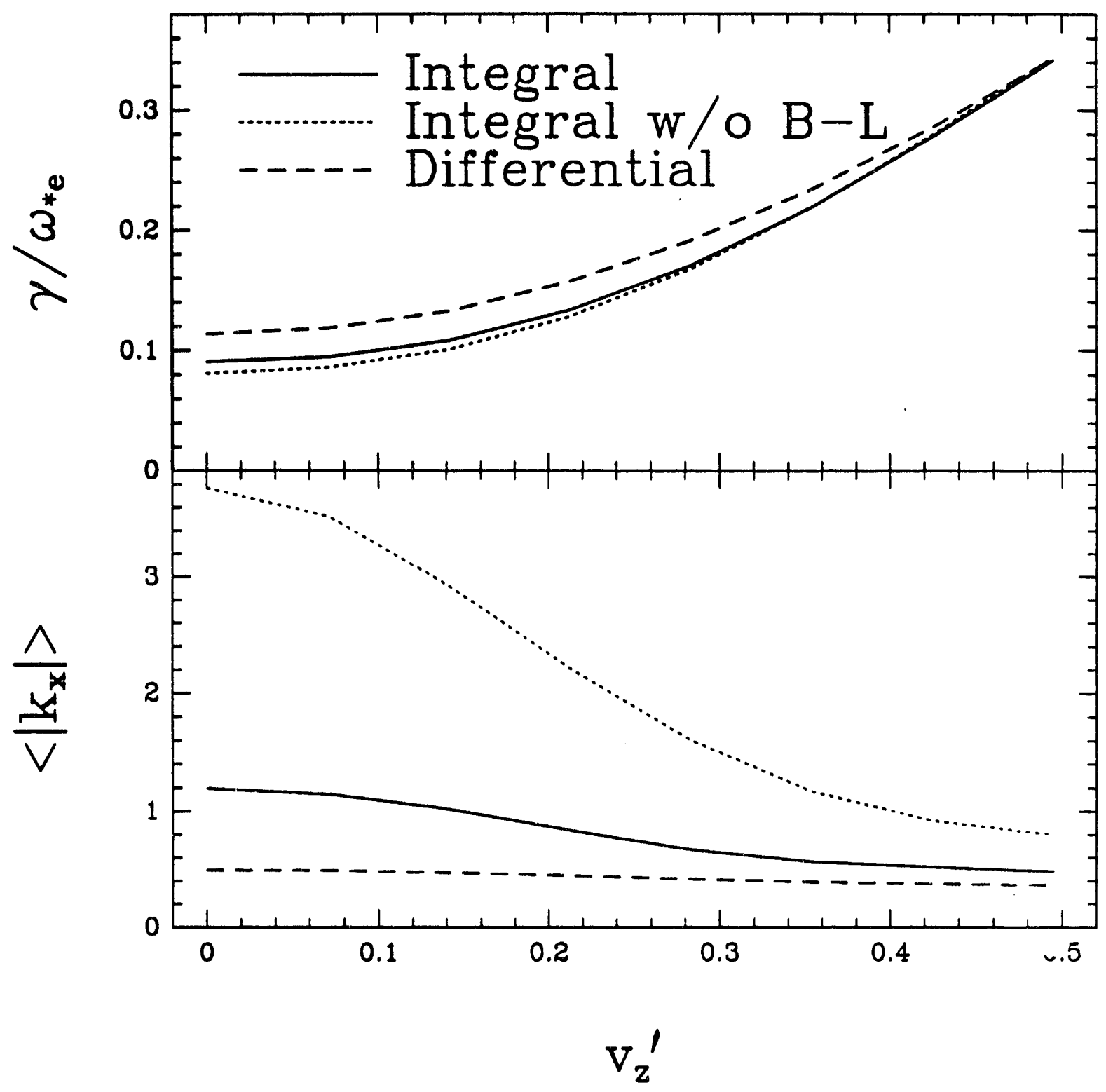

Figure 9: Growth rate $(\gamma)$ and average wavenumber $\left(\left\langle\left|k_{x}\right|\right\rangle\right)$ vs. $v_{z}^{\prime}$ for the integral, integral without the Bakshi-Linsker term, and differential approaches. Here, $\eta_{i}=3, \tau=1, L_{n} / L_{s}=$ $0.1, v_{y}^{\prime}=0$, and $L_{T} / L_{v}=1$. 


$$
\mathrm{v}_{\mathrm{z}}{ }^{\prime}=0.0 \quad \mathrm{v}_{\mathrm{z}}{ }^{\prime}=0.5
$$

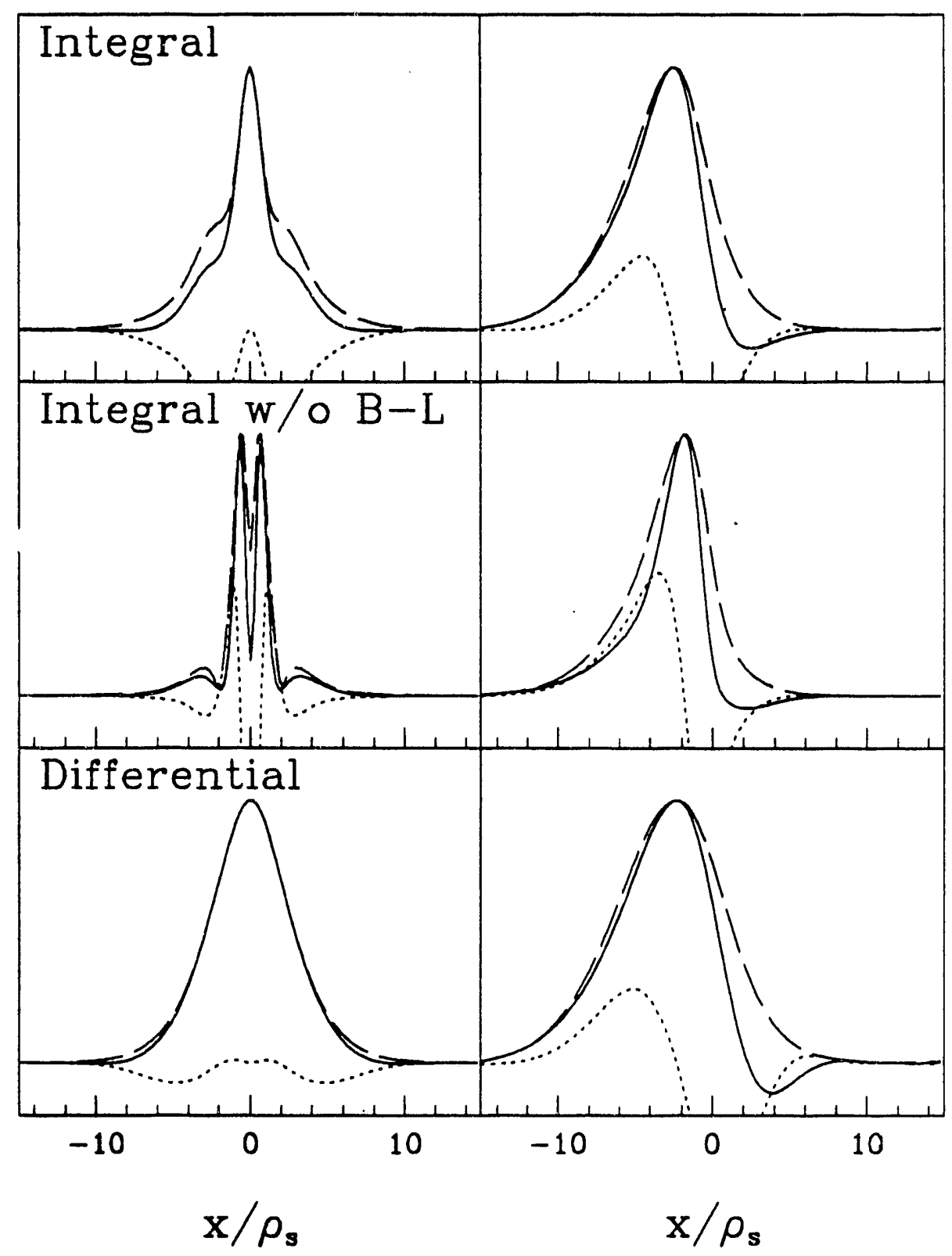

Figure 10: Eigenfunctions obtained by the integral, integral without the Bakshi-Linsker term, and differential approaches at $v_{z}^{\prime}=0$ and $v_{z}^{\prime}=0.5$. All other parameters are as in Fig. 9. 
Dr. F. Paoloni, Univ. of Woltongong. AUSTRALIA

Prot. M.H. Brennan, Univ. of Sydnoy, AUSTRALIA

Plasma Resaarch Leb., Austraien Nal Univ., AUSTRALIA

Prot. I.R. Jones, Flindars Univ, AUSTRALIA

Prof. F. Cap. Inst for Theoretical Physics, AUSTRIA

Prot. M. Heindter, Institut tor Theoretiscte Physik, AUSTAIA

Prot. M. Gooseans, Astronomisch Instituut, BELGIUM

Ecole Royado Mituire, Lab. do Phy. Plasmas, BELGIUM

Commission-Europeen, DG. XII-Fusion Prog., BELGIUM

Prof. R. Boucique, Rijksuniversiteit Genth BELGIUM

Dr. P.H. Sekenake, Instiuto Fivica, BRAZIL

Instituto Neciond Do Posquisas Espacisis-INPE, BRWZIL

Documents Ofice, Abmic Energy of Canada Ld., CANADA

Dr. M.P. Bectynekj, MPB Technologios, Inc., CANADA

Dr. H.M. Skarsaged, Univ. of Sackatchowen, CANADA

Prof. J. Teictrmam, Univ. of Montred, CANADA

Prot. S.R. Sreenivasen, Univ. of Calgary, CANADA

Prot. T.W. Johnston, INAS-Energio, CANADA

5r. R. Boton, Centro canadien de husion magnélique, CANADA

Dr. C.R. James., Univ. of Nborta, CANADA

Dr. P. Lukbe, Komonsketho Univorszit, CZECHOSLOVAKIA

The Librarian, Cuham Leborabry. ENGLAND

Library, R61, Ruthortord Applaton Laboratory, ENGLAND

Nrs. S.A. Hutctinison, JET Library. ENGLAND

Dr. S.C. Shama, Univ. of South Pacific, FIJI ISLANDS

P. Mahonen, Univ. of Helsinki, FINLAND

Prot. M.N. Buseac, Ecole Polytechnique, FRANCE

C. Mountat, Lob. de Physique des Milieux lonisés, FRANCE

J. Radat, CENCADARACHE - Bat 506, FRANCE

Prot. E. Economou, Univ. of Crote, GREECE

Ms. C. Rinni, Univ. of loamine, GREECE

Dr. T. Mud, Acactormy Bibliographic Sor., HONG KONG

Proprint Library, Hungarian Acadomy of Sci. HUNGARY

Dr. B. DasGupta, Saha Inst of Nuctear Physics, INDIA

Dr. P. Kaw, Inst. for Plasma Research, INDIA

D. P. Rosenew, leraed Inst. of Tectinotogy, ISPAEL

Libraian, Intomationa Conter for Theo Physics, ITALY

Miss C. Do Palo, Associaziono EURATOAENEA, ITALY

Dr. G. Grosso, Istutu di Fisica del Plasma, ITALY

Prof. G. Postangni, Istituto Gas lonizzati Dol Cnr, ITALY

Dr. H. Yamato, Toshiba Pos a Dovel Centor, JAPAN
Prof. I. Kawakami, Hiroshima Univ., JAPAN

Prof. K Nishikawa, Hiroshima Univ.. JAPAN

Director, Japan Atomic Energy Research Inst, JAPAN

Prot. S. Itoh, Kyustu Univ., JAPAN

Research Into. Cr., National Instit. for Fusion Science, JAPAN

Prot. S. Tanaka, Kyolo Univ., JAPAN

Libray, Kyoto Univ., JAPAN

Prot. N. Inowe, Univ. of Tokyo, JAPAN

Secrotary, Plasma Section, Electrotochnical Lab., JAPAN

S. Mori, Tectrinica Advieor, LiéRI, JAPAN

Dr. O. Mitsorai, Kumamow Inst of Technology, JAPAN

J. Hyeonsook, Korea Alomic Energy Rosearch Inst, KOREA

D.I. Choi, The Korea Adv. Inst. of Sai. \& Tech., KOREA

Prol. B.S. Liloy, Univ. of Waikato, NEW ZEALAND

Inst of Physics, Chinese Acad Sa PEOPLE'S REP. OF CHINA

Liorery, Inst of Plasma Physics, PEOPLE'S REP. OF CHINA

Tsinghua Univ. Libray, PEOPLE'S REPUBLIC OF CHINA

$Z$ L, S.W. Inst Physics, PEOPLE'S REPUBLUC OF CHINA

Prot. J.A.C. Cebre, Instituto Superior Tecnico, PORTUGAL

Dr. O. Potrus, Al I CUzA Univ., ROMANIA

Dr. J. Villiers, Fusion Studies, AEC, S. AFRICA

Prof. M.A. Hellberg, Univ. of Natal, S. AFRICA

Prof. D.E. Km, Pohang Inst. of Sai. Tech., SO. KOREA

Prot. C.I.E.MA.T, Fusion Division Library, SPAIN

Dr. L SEntlo, Univ. of UMEA, SWEDEN

Lbray, Royd Inst. of Tectnology, SWEDEN

Prof. H. Whotmeon, Chalmors Univ. of Tech., SWEDEN

Contro Phys. Des Plaemas, Ecole Polytech. SWITZERLAND

Bibliotheak, Inst. Voor Plesma-Fysica, THE NETHERLANDS

Asst. Prot. Dr. S. Cekir, Middle East Tech. Univ., TURKEY

Dr. V.A. Gukhikh,Sai. Res. Inst. Electrophys.I Apparatus, USSR

Dr. D.D. Ayubv, Siberian Branch of Academy of Sa., USSR

Dr. GA. Elieoev, I.V. Kurchatov inst. USSA

Librerien, The Ukr.SSR Academy of Scionces, USSR

Dr. LM. Kovrizinykh, Inst. of Genere Physics, USSR

Kerntorsctungeanlage GmbH, Zentrabibliothek, W. GERMANY Bibliothok, Inst. For Plasmatorecting. W. GERMANY Prof. K. Schinder, Ruhr-Universitat Bochum, W. GERMANY Dr. F. Wegner, (ASDEX), Max-Planck-institut, W. GERMANY Librarian, Max-Plendk-Institut, W: GERMANY

Prot. A.K. Janov, Inal of Ptyrica, YUGOSLAVIA 


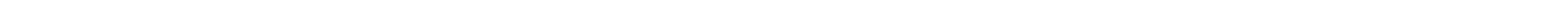




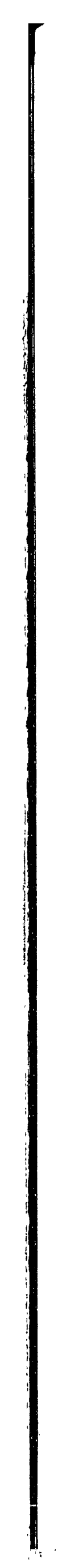

